\title{
Pengaruh Variasi Produk dan Kualitas Pelayanan terhadap Minat Beli Ulang Konsumen pada Coffeeville-Oishi Pan Magelang
}

\author{
Budi Lestari $^{1)}$, Ivo Novitaningtyas ${ }^{2)}$ \\ Universitas Tidar, Magelang, Indonesia \\ Email: budilestari766@gmail.com ${ }^{1)}$,ivo.novitaningtyas@untidar.ac.id²)
}

\begin{abstract}
This study aims to examine the effect of product variation and service quality on consumer repurchase interest at the Coffeville-Oishi Pan Magelang cafe. This study uses a quantitative approach. This study uses primary data obtained from 100 respondents as a sample selected based on the convenience sampling method. The data that has been collected was analyzed based on multiple linear regression analysis using SPSS. The results showed that product variations and service quality had a significant simultaneous effect on consumers' repurchase interest. The product variation has a positive and significant effect on consumer repurchase interest, but service quality has a positive and insignificant effect on consumer repurchase interest. The results provide managerial implications for Coffeville-Oishi Pan Magelang to increase product variety and improve health protocol-based services in order to increase consumer repurchase interest. With the increasing interest in repurchasing consumers, it is hoped that the cafe business that is run can develop and be sustainable.
\end{abstract}

Keywords: cafe, service quality, repurchase intention, product variety

\begin{abstract}
Abstrak
Penelitian ini bertujuan untuk menguji pengaruhi variasi produk dan kualitas pelayanan terhadap minat beli ulang konsumen pada cafe Coffevillage-Oishi Pan Magelang. Penelitian ini menggunakan pendekatan kuantitatif. Penelitian ini menggunakan data primer yang diperoleh dari 100 responden sebagai sampel yang dipilih berdasarkan metode convenience sampling. Data yang telah terkumpul dianalisis berdasarkan analisis regresi linier berganda menggunakan SPSS. Hasil penelitian menunjukkan bahwa variasi produk dan kualitas pelayanan berpengaruh signifikan secara simultan terhadap minat beli ulang konsumen. Adapun variasi produk memiliki pengaruh yang positif dan signifikan terhadap minat beli ulang konsumen, tetapi kualitas pelayanan memiliki pengaruh positif dan tidak signifikan terhadap minat beli ulang konsumen. Hasil memberikan implikasi manajerial bagi Coffevillage-Oishi Pan Magelang untuk meningkatkan variasi produknya dan meningkatkan layanan berbasis protokol kesehatan agar dapat meningkatkan minat beli ulang konsumen. Dengan meningkatnya minat beli ulang konsumen maka diharapkan agar bisnis cafe yang dijalankan dapat berkembang dan berkelanjutan.
\end{abstract}

Kata kunci: cafe, kualitas pelayanan, minat beli ulang, variasi produk

\section{Pendahuluan}

Perkembangan bisnis kuliner di Magelang yang semakin maju mengakibatkan adanya persaingan bisnis yang semakin ketat. Salah satu bisnis kuliner yang mengalami pertumbuhan adalah cafe. Peluang bisnis cafe di Magelang didukung oleh perilaku konsumen yang cenderung tertarik pada tempat makan atau minum sekaligus tempat bersantai. Adapun jumlah keseluruhan cafe di Magelang yaitu 25 cafe. Walaupun demikian, kemungkinan munculnya cafe-cafe baru dapat menjadi ancaman bagi cafe-cafe lama yang tidak mampu berinovasi dalam hal produk maupun layanannya.

Coffevillage-Oishi Pan adalah salah satu cafe yang ada di Magelang. Cafe ini terletak di J1. M.T Haryono, Cacaban, Magelang Tengah. Di masa pandemi Covid-19, cafe ini masih bertahan dan menjadi salah satu alternatif pilihan bagi konsumen di area Magelang. Berdasarkan hasil observasi, Coffevillage-Oishi pan merupakan salah cafe yang menawarkan produk beragam dan 
selalu berinovasi dengan menawarkan menu-menu baru bagi target konsumen. Selain itu, cafe ini juga sudah menerapkan layanan berbasis protokol kesehatan.

Walaupun demikian, di masa pandemi cafe ini mengalami penurunan penjualan hingga $30 \%$. Kondisi tersebut juga dialami oleh beberapa bisnis makanan dan minuman yang lainnya. Amri (2020) juga menjelaskan bahwa bisnis makanan dan minuman terdampak pandemi seperti mengalami penurunan penjualan, kekurangan modal, terhambat proses distribusi, dan terpaksa mengurangi sumber daya manusia (SDM). Berdasarkan kondisi tersebut, diharapkan agar Coffevillage-Oishi Pan mampu mempertahankan bisnisnya salah satunya dengan meningkatkan minat beli konsumen. Jika minat beli konsumen maka berpeluang meningkatkan penjualan dan pendapatan. Dengan demikian, faktor-faktor yang diduga dapat meningkatkan minat beli konsumen terhadap Coffevillage-Oishi Pan perlu diidentifikasi lebih lanjut.

Saputra, Mulyati, \& Andayani (2015) menjelaskan bahwa pada produk makanan atau minuman, variasi sangat berpengaruh untuk meningkatkan minat beli konsumen. Dengan demikian, pebisnis makanan dan minuman perlu terus berinovasi untuk meningkatkan variasi produk yang ditawarkan sehingga menarik minat konsumen untuk membelinya. Walaupun demikian, hasil penelitian lainnya membuktikan bahwa pengaruh dari variasi produk terhadap minat beli konsumen tidak signifikan (Hidayat \& Resticha, 2019). Hasil tersebut juga didukung oleh Peburiyanti \& Sabran (2020) yang menjelaskan bahwa pengaruh variasi produk terhadap minat beli ulang adalah positif tetapi tidak signifikan. Berdasarkan kesenjangan hasil pada penelitian terdahulu, maka hubungan antara variabel variasi produk dan minat beli ulang konsumen perlu diteliti lebih lanjut.

Kualitas pelayanan juga menjadi pertimbangan konsumen untuk memutuskan berkunjung kembali ke penyedia jasa atau layanan (Dewi, 2016; Ofela, 2016). Kualitas pelayanan yang buruk akan membuat konsumen tidak nyaman dan tidak berminat untuk datang kembali ke cafe, begitupun sebaliknya jika pelayanan yang diberikan berkualitas maka konsumen menjadi berminat untuk kembali berkunjung dan membeli produk yang ditawarkan. Pelayanan dari tempat makan dan minum atau cafe yang berkualitas dibuktikan dapat meningkatkan minat beli ulang dari konsumen (Faradisa, Budi, \& Minarsih, 2016; Hadani, 2008; Susanti, 2012). Hasil penelitian lainnya pada cafe membuktikan bahwa dimensi kualitas layanan memiliki pengaruh positif terhadap minat beli ulang, walaupun dampaknya tidak signifikan (Vinda, 2012). Berdasarkan hasil tersebut, maka pengaruh dari kualitas pelayanan terhadap minat beli ulang perlu diuji lebih lanjut.

Berdasarkan uraian di atas, maka penelitian tentang pengaruh variasi produk dan kualitas layanan terhadap minat beli ulang di ini Coffevillage-oishi Pan Magelang penting untuk dilakukan. Penelitian ini bertujuan untuk mengetahui bagaimana variasi produk dan kualitas pelayanan yang diberikan Coffevillage-oishi Pan Magelang selama Pandemi Covid-19 dapat mempengaruhi minat beli ulang konsumennya. Hasil penelitian diharapkan dapat bermanfaat dalam memberikan informasi tentang faktor-faktor yang dapat meningkatkan minat beli konsumen. Dengan demikian, manajemen perusahaan dapat menyusun kebijakan dan program dalam rangka meningkatkan kualitas layanan dan variasi produknya. Dengan meningkatnya minat beli ulang maka diharapkan agar bisnis Coffevillage-oishi Pan Magelang dapat bertahan di masa pandemi dan terus berkembang. 


\section{Tinjauan Pustaka}

\subsection{Minat Beli Ulang}

Minat beli adalah sebuah perilaku konsumen dimana konsumen mempunyai keinginan untuk membeli atau memilih suatu produk berdasarkan pengalaman dalam memilih, menggunakan dan mengkonsumsi atau bahkan menginginkan suatu produk (Muzakki, 2013). Adapun menurut Hidayat \& Resticha (2019) minat beli ulang merupakan minat pembelian yang didasarkan atas pengalaman pembelian yang telah dilakukan di masa lalu oleh konsumen. Lebih lanjut Peburiyanti \& Sabran (2020) menjelaskan bahwa minat beli ulang bisa diidentifikasi oleh beberapa indikator yaitu (1) minat refrensial yang merupakan minat seseorang untuk mereferensikan pada orang lain, (2) minat eksploratif yang merupakan minat seseorang mencari informasi pada produk yang diinginkannya, (3) minat transaksional yaitu kecenderungan untuk bertransaksi dan membeli produk, dan (4) minat preferensial yaitu minat yang menggambarkan perilaku seseorang yang memiliki preferensi utama pada produk tersebut.

\subsection{Variasi Produk}

Variasi produk atau keragaman produk bukan hal baru dalam dunia pemasaran. Strategi ini banyak digunakan oleh praktisi-praktisi pemasaran di dalam aktivitas peluncuran produknya. Menurut Faradisa et al. (2016) variasi produk dijelaskan sebagai merek atau lini produk yang dapat dibedakan berdasarkan ukuran, harga, penampilan, atau ciri-ciri tertentu. Berdasarkan pengertian menurut berbagai para ahli tersebut dapat disimpulkan bahwa variasi produk adalah strategi perusahaan dengan meningkatkan keanekaragaman produknya dengan tujuan agar konsumen mendapatkan produk yang diinginkan dan dibutuhkannya. Variasi produk merupakan hal yang harus diperhatikan oleh perusahaan untuk meningkatkan kinerja produk. Jika produk tersebut tidak beragam maka produk tersebut tentu akan kalah bersaing dengan produk yang lain. Menurut Istiqomah (2019) indikator yang berkaitan dengan variasi produk adalah dimensi lebar yaitu banyaknya jumlah jenis atau tipe (kategori) produk yang dijual, serta dimensi kedalaman yaitu banyaknya jumlah pilihan (ukuran, bahan, atau warna) atau masingmasing jenis atau tipe produk (kategori) yang dijual.

\subsection{Kualitas Pelayanan}

Kualitas pelayanan diidentifikasi berdasarkan dimensi SERVQUAL (Service Quality) (Nuraeni, 2014; Schiffman \& Kanuk, 2008). Dimensi bentuk fisik atau yang berwujud (tangibles) meliputi kualitas fisik seperti perlengkapan, peralatan, pegawai dan sarana komunikasi. Dimensi keandalan (reliability) adalah kemampuan memberikan pelayanan yang dijanjikan dengan segera, akurat dan memuaskan. Dimensi daya tanggap (responsiveness) adalah respon para staf untuk membantu pelanggan dan memberikan pelayanan yang tanggap. Dimensi jaminan (assurance) mencakup pengetahuan, kemampuan, kesopanan dan sifat layanan yang dapat dipercaya, sedangkan dimensi empati (emphaty) meliputi kemudahan dalam melakukan hubungan, komunikasi yang baik, perhatian pribadi dan memahami kebutuhan para pelanggan.

\section{Metode Penelitian}

Penelitian ini menggunakan pendekatan kuantitatif. Penelitian kuantitatif digunakan untuk menguji sampel tertentu dalam populasi melalui instrumen penelitian dalam pengumpulan data, dan analisis data dilakukan dengan menggunakan statistik kuantitatif untuk menguji hipotesis (Sugiyono, 2013). Desain penelitian adalah desain kausal untuk memahami hubungan sebab akibat atau kausalitas dari variabel-variabel yang diteliti (Suhartanto, 2014). Populasi dalam penelitian ini adalah seluruh konsumen dari Coffevillage-Oishi Pan Magelang. Adapun jumlah 
populasi tidak diketahui secara pasti, sehingga besar sampel ditentukan oleh 100 responden. Jumlah ini dianggap memenuhi ukuran sampel antara 30-500 (Ghozali, 2017). Pengambilan sampel dilakukan dengan menggunakan metode convenience sampling dengan pertimbangan memilih sampel yang paling mudah dijangkau untuk memberikan informasi yang dibutuhkan dalam penelitian. Jenis data yang digunakan dalam penelitian ini adalah data primer yang diperoleh langsung dari responden melalui kuesioner. Kuesioner yang digunakan dalam penelitian ini adalah jenis pertanyaan tertutup dimana responden cukup memilih salah satu alternatif jawaban dari pertanyaan tersebut. Skala likert digunakan untuk mengukur persepsi responden terhadap indikator variabel penelitian. Data yang telah terkumpul kemudian dianalisis berdasarkan analisis regresi linier berganda menggunakan SPSS. Variabel yang diteliti dalam penelitian ini yaitu variasi produk dan kualitas pelayanan sebagai variabel independen dan minat beli ulang sebagai variabel dependen.



Gambar 1. Kerangka Konseptual

\section{Hasil dan Pembahasan}

\subsection{Uji Validitas dan Reliabilitas}

Hasil uji validitas menunjukkan bahwa seluruh item yang merupakan indikator dari variabel Variasi Produk, Kualitas Pelayanan dan Minat Beli Ulang dinyatakan valid. Hasil tersebut dibuktikan dari nilai r-hitung yang lebih besar dibandingkan dengan r-tabel. Adapun r-tabel untuk jumlah 100 responden adalah 0,196 sehingga seluruh item dalam kuesioner yang memiliki nilai lebih besar dari 0,196 dinyatakan valid.

Tabel 1. Hasil Uji Validitas Variabel Variasi Produk

\begin{tabular}{ccccc}
\hline Variabel & Item & r-hitung & r-tabel & Hasil \\
\hline Variasi Produk & X1.1 & 0,348 & 0,196 & Valid \\
& X1.2 & 0,348 & 0,196 & Valid \\
& X1.3 & 0,390 & 0,196 & Valid \\
\hline
\end{tabular}


Sumber: Data Diolah 2021

Tabel 1 menunjukkan bahwa 3 item yang merupakan indikator dari variabel variasi produk dinyatakan valid. Selanjutnya Tabel 2 dan Tabel 3 juga menunjukka nbahwa 5 indikator dari variabel kualitas pelayanan dan 4 indikator dari variabel minat beli ulang memiliki nilai r-hitung yang lebih besar dari r-tabel sehingga juga dikategorikan valid. Hasil membuktikan bahwa seluruh item dalam instrumen yang digunakan pada penelitian ini terbukti valid.

Tabel 2. Hasil Uji Validitas Variabel Kualitas Pelayanan

\begin{tabular}{ccccc}
\hline Variabel & Item & r-hitung & r-tabel & Hasil \\
\hline Kualitas Pelayanan & X2.1 & 0,318 & 0,196 & Valid \\
& X2.2 & 0,374 & 0,196 & Valid \\
X2.3 & 0,235 & 0,196 & Valid \\
X2.4 & 0,272 & 0,196 & Valid \\
& X2.5 & 0,296 & 0,196 & Valid \\
\hline
\end{tabular}

Sumber: Data Diolah 2021

Tabel 3. Hasil Uji Validitas Variabel Minat Beli Ulang

\begin{tabular}{ccccc}
\hline Variabel & Item & r-hitung & r-tabel & Hasil \\
\hline Minat Beli Ulang & Y1 & 0,740 & 0,196 & Valid \\
& Y2 & 0,172 & 0,196 & Valid \\
& Y3 & 0,240 & 0,196 & Valid \\
& Y4 & 0,268 & 0,196 & Valid \\
\hline
\end{tabular}

Sumber: Data Diolah 2021

Selanjutnya, uji reliabilitas dilakukan dengan menggunakan analisis Cronbach-Alpha. Suatu variabel dinyatakan reliabel jika nilai cronbach alpha melebihi 0,7 (Ghozali, 2011). Hasil penelitian menunjukkan bahwa semua item yang merupakan indikator dari variabel dalam penelitian ini dinyatakan reliabel. 
Tabel 4. Hasil Uji Reliabilitas

\begin{tabular}{ccc}
\hline Cronbach Alpha & N of Items & Hasil \\
\hline 0,754 & 12 & Reliabel \\
\hline
\end{tabular}

Sumber: Data Diolah 2021

\subsection{Uji Asumsi Klasik}

Gambar 2 menunjukkan hasil uji normalitas bahwa penyebaran data berada disekitar garis diagonal dan penyebarannya mengikuti arah garis diagonal grafik tersebut. Berdasarkan hasil tersebut maka model regresi yang digunakan dalam penelitian ini memenuhi asumsi normalitas yang berarti distribusi penyebaran datanya normal.



Gambar 2. Hasil Uji Normalitas

Adapun Tabel 5 menunjukkan bahwa hasil uji multikolinearitas. Hasil menunjukan bahwa tidak terjadi gejala multikolinearitas karena variabel Variasi Produk, Kualitas Pelayanan dan Minat Beli Ulang memiliki nilai VIF $<10$ dan nilai tolerance $>0,01$.

Tabel 5. Hasil Uji Multikolinearitas

\begin{tabular}{ccc}
\hline Variabel & Tolerance & VIF \\
\hline Variasi Produk & 0,658 & 1,519 \\
Kualitas Pelayanan & 0,658 & 1,519 \\
Minat Beli Ulang & 0,658 & 1,519 \\
\hline
\end{tabular}

Sumber: Data Diolah 2021 


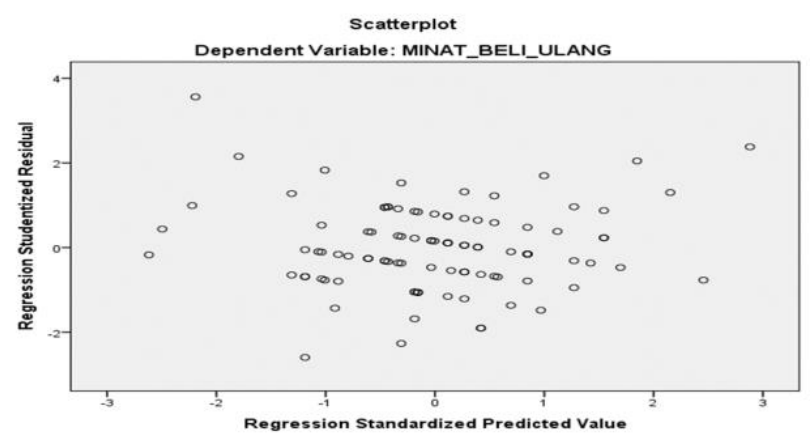

Gambar 3. Hasil Uji Heteroskedastisitas

Hasil uji heteroskedastistas pada Gambar 3 menunjukan bahwa titik titik menyebar secara acak diatas dan dibawah angka 0 pada sumbu $\mathrm{Y}$ dan tidak membentuk pola yang jelas, maka dapat dikatakan bahwa tidak terjadi heteroskedastistas pada model regresi sehingga layak digunakan untuk memprediksi variabel Minat Beli Ulang Konsumen (Y).

\subsection{Analisis Regresi Linier Berganda}

Tabel 6. Hasil Uji Analisis Regresi Linier Berganda

\begin{tabular}{|c|c|c|c|c|c|c|}
\hline \multirow{2}{*}{$\begin{array}{l}\text { Variabel } \\
\text { Dependen }\end{array}$} & \multirow{2}{*}{$\begin{array}{c}\text { Variabel } \\
\text { Independen }\end{array}$} & \multicolumn{2}{|c|}{$\begin{array}{l}\text { Unstandardized } \\
\text { Coefficients }\end{array}$} & $\begin{array}{l}\text { Standardized } \\
\text { Coefficients }\end{array}$ & \multirow{2}{*}{$\mathrm{t}$} & \multirow{2}{*}{ sig. } \\
\hline & & B & $\begin{array}{l}\text { Std. } \\
\text { Error }\end{array}$ & Beta & & \\
\hline \multirow{3}{*}{$\begin{array}{l}\text { MINAT BELI } \\
\text { ULANG (Y) }\end{array}$} & $(\cos \tan t)$ & 10.587 & 1.226 & & 8.637 & .000 \\
\hline & $\begin{array}{c}\text { VARIASI } \\
\text { PRODAK (X1) }\end{array}$ & .243 & .115 & .249 & 2.114 & .037 \\
\hline & $\begin{array}{l}\text { KUALITAS } \\
\text { PELAYANAN } \\
\text { (X2) }\end{array}$ & .087 & .079 & .130 & 1.104 & .272 \\
\hline
\end{tabular}

Sumber: Data Diolah 2021

Dari data pada Tabel 6 maka dapat dihasilkan suatu model persamaan sebagai berikut:

$\mathrm{Y}=10.587+0,243 \mathrm{X} 1+0,087 \mathrm{X} 2+\mathrm{e}$

Nilai konstanta (a) sebesar 10.587 yang berarti bahwa tanpa adanya variabel Variasi Produk (X1) dan Kualitas Pelayanan (X2) seluruhnya dianggap 0, maka Minat Beli ulang (Y) memiliki nilai konstan sebesar 10.587. Jadi apabila variabel bebas (X1, X2) konstan maka nilai Minat Beli Ulang sebesar 10.587.

Nilai koefisien $\left(\beta_{1}\right)$ pada variabel Variasi Produk (X1) sebesar 0,243 memiliki arti bahwa jika variabel kualitas pelayanan bernilai nol, maka variasi produk adalah 0,243 . Jadi apabila variasi produk meningkat satu satuan maka akan meningkatkan juga Minat Beli Ulang sebesar 0,243. 
Nilai koefisien $\left(\beta_{2}\right)$ pada variabel Kualitas Pelayanan (X2) sebesar 0,087 memiliki arti bahwa jika variabel variasi produk bernilai nol, maka minat beli ulang adalah 0,087. Jadi apabila variabel kualitas pelayanan meningkat satu satuan maka akan meningkatkan juga Minat Beli Ulang sebesar 0,87 .

Adapun Variasi Produk (X1) memiliki nilai signifikansi 0,037<0,05. Artinya variabel Variasi Produk mempunyai pengaruh yang signifikan terhadap Minat Beli Ulang Konsumen (Y). Hasil ini mendukung penelitian terdahulu yang menyatakan bahwa pengaruh variasi produk terhadap minat beli ulang positif dan signifikan (Saputra et al., 2015). Hal tersebut berarti bahwa semakin bervariasi produk berupa menu makanan atau minuman yang ditawarkan oleh CoffevillageOishi Pan Magelang, maka akan semakin berminat konsumennya untuk melakukan pembelian ulang terhadap produk makanan atau minuman yang ditawarkan. Namun sebaliknya, semakin rendah atau sedikit variasi produk yang ada di Coffevillage-Oishi Pan Magelang, maka semakin rendah pula minat beli ulang konsumen Coffevillage-Oishi Pan Magelang. Hasil ini memberikan implikasi manajerial bagi Coffevillage-Oishi Pan Magelang untuk menambah variasi produknya.

Lebih lanjut, Kualitas Pelayanan (X2) memiliki nilai signifikansi 0,272 >0,05. Hasil tersebut menunjukkan bahwa variabel Kualitas Pelayanan mempunyai pengaruh yang tidak signifikan terhadap Minat Beli Ulang konsumen (Y) pada Coffevillage-Oishi Pan Magelang. Temuan ini tidak sesuai dengan beberapa hasil penelitian terdahulu yang menyatakan bahwa pengaruh kualitas pelayanan terhadap minat beli ulang konsumen adalah signifikan (Faradisa et al., 2016; Hadani, 2008; Susanti, 2012). Walaupun demikian, hasil penelitian ini sejalan dengan penelitian Vinda (2012) yang juga memiliki temuan bahwa pengaruh kualitas pelayanan terhadap minat beli ulang tidak signifikan pengaruhnya. Selama pandemi Covid-19 memang Pemerintah menerapkan kebijakan Pemberlakuan Pembatasan Kegiatan Masyarakat (PPKM) dan salah satu dampaknya adalah cafe maupun restoran tidak diizinkan untuk melayani makan atau minum di tempat (dine in). Hal tersebut diperkirakan telah mengubah persepsi konsumen CoffevillageOishi Pan Magelang, sehingga para konsumen tidak terlalu mempertimbangkan kualitas pelayanan yang diberikan karena mereka tidak bisa makan dan minum di tempat.

Tabel 7. Hasil Uji F

\begin{tabular}{ccccccc}
\hline & & $\begin{array}{c}\text { Sum of } \\
\text { Squares }\end{array}$ & df & $\begin{array}{c}\text { Mean } \\
\text { Square }\end{array}$ & F & Sig. \\
\hline 1 & Regression & 32,404 & 2 & 16,202 & 6,393 & .002 \\
& Residual & 245,836 & 97 & 2,534 & & \\
Total & 278,240 & 99 & & & \\
\hline
\end{tabular}

Sumber: Data Diolah 2021

Adapun hasil uji F menunjukkan hasil bahwa nilai signifikansi 0,002. Nilai tersebut lebih kecil dari 0,05 maka dapat diartikan bahwa variabel Variasi Produk (X1) dan variabel Kualitas Pelayanan (X2) memiliki pengaruh yang signifikan secara simultan terhadap Minat Beli ulang 
(Y) di Coffevillage-Oishi Pan Magelang.

Hasil penelitian ini memberikan implikasi praktis atau manajerial bagi Coffevillage-Oishi Pan Magelang untuk menyusun rencana inovasi produk dengan menambah variasi produk dan meningkatkan kualitas pelayanannya dalam rangka meningkatkan minat beli ulang konsumen. Hasil penelitian juga memberikan implikasi teoretis sehingga dapat digunakan sebagai sumber referensi bagi peneliti selanjutnya. Adapun penelitian ini dibatasi pada penggunaan dua variabel bebas yaitu variasi produk dan kualitas pelayanan dalam model penelitian. Saran bagi peneliti selanjutnya dapat mengembangkan model penelitian dengan menambahkan variabel independen lainnya yang diduga mempengaruhi minat beli ulang konsumen atau menambahkan variabel moderasi dan mediasi. Selain itu, penelitian selanjutnya juga dapat menggunakan teknik analisis data lain yang relevan dan melakukan penelitian pada objek cafe lainnya.

\section{Kesimpulan}

Pengujian secara simultan terhadap variabel Minat Beli Ulang yang terdiri dari variabel Variasi Produk dan Kualitas Pelayanan menunjukkan bahwa terdapat pengaruh yang signifikan secara simultan. Kemudian, uji parsial menunjukkan hasil bahwa variabel Variasi Produk berpengaruh positif dan signifikan terhadap Minat Beli Ulang, sedangkan Kualitas Pelayanan berpengaruh positif tetapi tidak signifikan terhadap Minat Beli Ulang pada konsumen Coffevillage-Oishi Pan Magelang. Hasil penelitian memberikan implikasi manajerial bagi bisnis cafe untuk dapat meningkatkan variasi produk makanan dan minuman yang ditawarkan kepada konsumen, sehingga dapat meningkatkan minat beli ulang konsumen terutama di masa pandemi. Lebih lanjut, peningkatan kualitas layanan berbasis protokol kesehatan juga diperlukan agar minat beli ulang konsumen juga meningkat. Dengan meningkatkan minat beli ulang konsumen, diharapkan agar penjualan dan pendapatan dari bisnis cafe dapat meningkat sehingga bisnisnya dapat bertahan di masa pandemi, berkembang dan berkelanjutan. Hasil penelitian ini juga dapat menjadi acuan bagi penelitian selanjutnya untuk mengembangkan model penelitian dan faktorfaktor yang dapat meningkatkan minat beli ulang konsumen khususnya pada bisnis cafe.

\section{Referensi}

Amri, A. (2020). Dampak Covid-19 Terhadap UMKM di Indonesia. Jurnal Brand, 2(1), 147153.

Dewi, A. R. (2016). Pengaruh Kualitas Produk, Harga, Lokasi, Dan Kualitas Layanan Terhadap Keputusan Pembelian Di Djawi Lanbistro Coffee and Resto Surabaya. Jurnal Pendidikan Tata Niaga (JPTN), 3(3).

Faradisa, I., Budi, L., \& Minarsih, M. M. (2016). Analisis Pengaruh Variasi Produk, Fasilitas, dan Kualitas Pelayanan Terhadap Minat Beli Ulang Konsumen pada Indonesian Coffeeshop Semarang (ICOS CAFÉ). Journal of Management, 2(2), 1-13.

Ghozali, I. (2011). Aplikasi Analisis Multivariate Dengan Program IBM SPSS 19 (edisi kelima). Semarang: Universitas Diponegoro.

Ghozali, I. (2017). Model Persamaan Struktural Konsep dan Aplikasi Dengan Program AMOS 24 Update Bayesian SEM Edisi 7. Semarang: Badan Penerbit Universitas Diponegoro.

Hadani, A. L. (2008). Analisis Pengaruh Kualitas Layanan Terhadap Minat Beli Ulang (Studi Empiris Pada Pt. Sriwijaya Air Distrik Semarang ). Jurnal Bisnis Strategi, 8(3), 241-275. https://doi.org/10.14710/jbs.17.2.128-159 
Hidayat, R., \& Resticha, D. (2019). Analisis Pengaruh Variasi Produk Dan Labelisasi Halal Terhadap Kepuasan Konsumen Untuk Meningkatkan Minat Beli Ulang Pada Kosmetik Wardah. Journal of Business Administration, 3(1), 40-52. https://doi.org/10.30871/jaba.v3i1.1282

Istiqomah, L. (2019). Pengaruh Citra Merek, Suasana Toko, Variasi Produk, Kualitas Pelayanan dan Harga terhadap Keputusan Pembelian di Resto X. Journal of Chemical Information and Modeling, 53(9), 1689-1699.

Muzakki, A. (2013). Analisis Pengaruh Kualitas Pelayanan, Lokasi, Harga dan Fasilitas Terhadap Minat Beli Ulang Konsumen. 119.

Nuraeni, B. S. (2014). Analisis Faktor-Faktor Yang Mempengaruhi Minat Kunjung Ulang Wisatawan Museum Ranggawarsita Semarang. Jurnal Bisnis Strategi, 23(1), 1-20. Retrieved from https://ejournal.undip.ac.id/index.php/jbs/article/viewFile/14113/10711

Ofela, H. (2016). Pengaruh harga, kualitas produk dan kualitas pelayanan terhadap kepuasan konsumen kebab kingabi. Jurnal Ilmu Dan Riset Manajemen, 5(1), 1-15.

Peburiyanti, D., \& Sabran, S. (2020). Pengaruh Promosi Penjualan, Variasi Produk Dan Kualitas Pelayanan Terhadap Minat Beli Ulang Pada Butik Kanabini Di Tenggarong. Jurnal Ekonomi Dan Manajemen Indonesia, 20(1), 29-39.

Saputra, V. N., Mulyati, A., \& Andayani, S. (2015). Analisis Pengaruh Variasi Produk, Cita Rasa, dan Higienitas Terhadap Minat Beli Konsumen (Studi Kasus Pada Ice Cream Zangrandi Surabaya). Jurnal Dinamika Administrasi Bisnis, 1(2), 1-14. Retrieved from http://jurnal.untag-sby.ac.id/index.php/adbis/article/view/2322

Schiffman, L., \& Kanuk, L. L. (2008). Perilaku Konsumen. Jakarta: PT Indeks.

Sugiyono. (2013). Metode Penelitian Bisnis (Pendekatan Kuantitatif, Kualitatif dan R\&D). Bandung: Penerbit Alfabeta.

Suhartanto, D. (2014). Metode Riset Pemasaran. Bandung: Penerbit Alfabeta.

Susanti, T. (2012). ANALISIS PENGARUH KUALITAS PRODUK, HARGA, LOKASI DAN KUALITAS PELAYANAN TERHADAP KEPUTUSAN PEMBELIAN (Studi pada Waroeng Spesial Sambal cabang Tembalang, Semarang). Ekonomika Dan Bisnis Manajemen.

Vinda, L. (2012). Analisis Pengaruh Kualitas Pelayanan dan Kualitas Produk Terhadap Minat Beli Ulang ( Studi pada Starbucks Semarang ). Universitas Diponegoro, 1-13.

\section{Copyrights}

Copyright for this article is retained by the author(s), with first publication rights granted to the journal.

This is an open-access article distributed under the terms and conditions of the Creative Commons Attribution license (http://creativecommons.org/licenses/by/4.0/) 